\title{
Looking Elsewhere: Howard S. Becker as Unwilling Organisational Theorist
}

\begin{abstract}
This paper explores the idea of Howard $\mathrm{S}$. Becker as organisational theorist. It examines some of the principal conceptual imagery in Becker's work, and considers the significance of this imagery for how organisations are 'seen' (conceptualised) and 'looked at' (analysed). To this end, a critical comparison of Becker's concept of world and Bourdieu's concept of field is undertaken. By his own admission, Becker recognises that some of his key studies - of art worlds, jazz musicians, educational environments, and so forth - might be recast as centrally 'about organisations'. However, it is argued that Becker is something of an 'unwilling' organisational theorist; not in the sense that he avoids or is ignorant of the conceptual debates invoked by that term, but in as much as formal theory without object is profoundly at odds with key aspects of his sociological practice. Accordingly, the paper centrally considers how Becker has consistently 'looked elsewhere' in much of his work. 'Looking elsewhere', it is proposed, involves reframing key conceptual and methodological problems such that they are amenable to research. It also involves an often radical rejection of the framing of certain kinds of problem, points towards alternative modes of analysis and investigation, and entails the development of conceptual imagery expressly intended to avoid the restrictions and confinement of now dominant forms of analytical convention.
\end{abstract}

Keywords: Becker, Organisational Sociology, Conceptual Imagery, World, Field, Structure, Agency, Power 


\section{Introduction}

The original working title for this paper was 'Howard S. Becker as Unwitting Organisational Theorist'. The impetus behind the title was the idea that Becker's work, though not often thought of as 'theoretical', nonetheless contains a series of remarkably consistent conceptual principles and analytical motifs which, arguably, have major significance for organisational theory. The aim of the paper, then, was to distil from the overall corpus of Becker's work some of its key theoretical and methodological principles and precepts, and then to go on to locate these in relation to current debates within the field. When I pitched the idea of this paper, along with its working title, to Becker himself, he immediately rejected the notion that he was an 'unwitting' organisational theorist. In his e-mailed reply, Becker wrote:

I'm not an unwitting organizational theorist, I'm an unwilling one, I think that's a distinction with a difference. Of course, I think that most of what l've done is about organizations, though I think many people would be surprised to hear that. I mean, the books about medical students and college students are all about organizations, and the last several pages of Art Worlds offers up a generalization of the whole preceding book that is indeed really about organizations too. The book with Faulkner on jazz, likewise (Becker 2012).

That Becker drew this pointed distinction already provides a more general insight into his sociological practice: his approach to formal theorising and his views on social theory as an enterprise in its own right; the frequent discrepancy between how others view Becker's work and how he sees it himself; and indeed, how one might recast and reconsider some of his key studies as centrally 'about organizations'. On the strength of these and further exchanges via email, I subsequently conducted a lengthy interview with Becker over Skype. The transcript of this interview, together with the personal correspondence (both of which he has permitted me to cite here) will be drawn upon throughout the following discussion so as to facilitate a dialogue with, through, and against Becker. In relation to the latter, I contrast Becker's way of 'looking' at organisations with that of Bourdieu - a figure who remains to be widely cited in contemporary organisational studies, and who in important respects presents a critical counterpoint to a Beckerian approach to imagining organisations. In particular, the contrast between Becker's concept of 'world' and Bourdieu's concept of 'field', which I 
shall explore in some detail, serves to illustrate how Becker both 'sees' (conceptualises) and 'looks at' (analyses) organisations in ways that are in important respects distinctive, and which have significance for enduring debates in organisational studies. In this way, the paper still retains several of its core aims as it was originally conceived, however, it also goes beyond these through a central focus upon Becker's seeming ambivalence towards, and response to, some of the conceptual preoccupations - particularly those surrounding power/knowledge, structure, and agency - that in recent years have come to figure prominently in debates within organisational theory, and the social sciences more generally.

The core argument I advance in this paper is that Becker's ostensible neglect of conceptual questions, his apparent hesitance to expound formal theory, is in important respects not really a neglect or hesitance at all. Nor do such tendencies stem from theory avoidance. Rather, they form part and parcel of his more general approach to social analysis which at its core involves translating and recasting abstract conceptual dilemmas into topics to be researched. It is an approach that also involves, often quite consciously, 'looking elsewhere': of radically rejecting conventional ways of posing certain kinds of problems, and concomitantly of pursuing alternative modes of analysis and investigation. The visual metaphors I employ throughout this paper - of Becker's 'looking' and 'seeing' - are not incidental, they chime with both the formal and substantive concerns of his approach to social analysis. Becker's 'looking elsewhere' has led him towards sometimes novel empirical sites; has underpinned a series of methodological innovations; and has more generally spurred the development of a diverse portfolio of pioneering research in relation to areas that have subsequently become well-established fields within their own right. Viewed in this way, we might reimagine Becker's work as a forerunner of some of the major themes in contemporary organisational scholarship that have followed the 'cultural turn' - language, identity, representation, meaning, social and cultural production, the contingency of knowledge and knowing, visual culture, and so forth - albeit that he did not frame his analyses in relation to debates about, say, new forms of capitalism, nor has he subsequently done so. In addition, then, to an exposition of a few of the theoretical continuities to Becker's work, I shall examine his reluctance to adopt (now) standard conceptual frames from the lexicon of social theory, and will centrally consider why in certain cases he has pointedly chosen to look elsewhere and equally has encouraged others to do so 
through promoting conceptual imagery expressly intended to escape the restrictions of certain forms of analytical convention. Ultimately, I reflect on the more general implications of Becker's approach for contemporary organisational theory and research.

\section{'Organisation' and Organisations: Looking Elsewhere}

It is first worth recounting how Becker, in our interview exchange, responded to my question of how he felt about the depiction of 'Howard S. Becker as Organisational Theorist'. He responded:

Well I am always interested in what people make of the things I have said... when I took my $\mathrm{PhD}$ exams we got to choose from several fields. Among them were social organisation and social psychology. Social organisation essentially meant everything that wasn't demography or social psychology. The other two possibilities were theory and methods. So in other words, the grand division was demography, social organisation, and social psychology ... it had none of the connotations of being related to management or business schools or anything like that. So I am an old fashioned social organisation type.

It is in itself noteworthy that the study of organisations has become, within certain circles at least, largely synonymous with the study of management, work and industry, and more generally, the intellectual sphere pertaining to management and business schools. The longer-standing set of connotations to which Becker alludes in his response has the broader sense of referring to 'patterns' of social relationships; perhaps kinship structures, institutional arrangements, or more general social 'systems' and their 'integration'. The sense in which 'organisation' might signal a particular academic field, or perhaps better, a specific set of interests expressing various relationships between the academy, business, industry and management - and the kinds of problems with which these groups typically concern themselves - is not lost on Becker. Rather, he is here challenging the axiom that we can proceed from a common assumption concerning what 'organisational studies' entails. ${ }^{\text {' }}$

In an interview with Brian Moeran (2012) Becker makes a similar point. When asked what the topic of 'business anthropology' means to him, Becker identifies two distinct ways in which he might answer that question. The first is, 'nothing more than good 
anthropology or sociology ... done in an organization or community that engages in business as conventionally defined' (2012: 248). Becker goes on to highlight two key studies - Melville Dalton's Men Who Manage and Robert Jackall's Moral Mazes - as exemplars of this kind of research. These studies share a concern with how organisations can operate in ways that run counter to conventional understandings of management and organisation. Thus, in Men Who Manage, Dalton (1959) explores employee theft as part of an institutionalised system of reciprocal organisational exchange. Similarly, Jackall (1988) examines how the appropriate negotiation of 'moral mazes' through the identification and application of 'rules in use' is a core part of corporate managers' occupational struggle, and a key basis for their development and promotion. Indeed, both problematize the idea of management as involving formal, planned, and rational forms of conscious control. As an extension of this point, Becker recounts the story of sitting next to a business executive on an international flight who claimed to have instituted a 'cultural change' in his organisation. Becker asked him to elaborate upon how the process was undertaken. The executive explained that he had enlisted an expert consultant who decided what the new culture should be and how this should be 'enacted' by employees. In turn, Becker explained that as a sociologist, he understood culture as 'a set of shared solutions people worked out themselves to problems they had in common', as such, instructing them by fiat to 'enact' a new culture meant he had in fact given his employees just one further problem for which they would need to devise a collective solution (Becker in Moeran 2012: 250). At this point, the conversation came to an abrupt end. On his personal website, Becker lists as one of his treasured, self-penned quotes, 'Management is a one-word oxymoron'. .'

The other sense of 'business anthropology' that Becker identifies is 'making a business out of anthropology' - for instance, people who research shopping habits, who track patterns of consumption by demographic, and so forth. Such research, Becker suggests, typically 'takes the client's questions ... there are always clients in this form of research ... as givens. What the client wants to know is what the researcher wants to find out' (2012: 248). As such, certain questions are off limits, others are not even considered. Becker recounts an anecdote from Boys in White - the (1961) study of a Kansas medical school he undertook together with Blanche Geer, Everett Hughes, and Anselm Strauss. He recalls being pulled up by a member of the medical school's 
faculty upon his (the faculty member's) rather angry realisation that Becker was studying him, not the students. He uses the example to illustrate a more general point:

That's almost invariably what happens when you study schools. You study the students because they are the problem. Of course, as a social scientist, you know that the problems of an organization are the problems of a whole organization, not some part of it, with other parts off limits to investigation (2012: 249).

Accordingly, when educational researchers typically research schools they might look at problems of differential attainment according to ethnicity, gender, class; student retention and truancy; pedagogy, etc. They tend not to look at why Mr Fletcher, our history teacher, is such a dick. Similarly, Becker argues, people engaged in business/management-commissioned research characteristically proceed from the starting point that their chief concerns stem from issues relating to employees or customers. As such, the possibility that those who have paid for the research might be implicated in 'the problem' is all but ruled out.

Becker's point pertains to more than simply questioning the structure of funding surrounding organisational research, or of looking at how the findings of research are contingent upon the interests of particular social groups. It relates to some of the more general characteristics of his sociological approach: of thinking through the very formulation of particular research problems; of approaching the research process itself as a collective form of common enterprise (and at that, one profoundly worthy of investigation); and of finding different 'ways in' to particular social arenas. Indeed, there is a substantial body of organisational research that takes as its point of departure the idea that the managerial prerogative should not be the defining concern for studies in the field (for a discussion of this tradition in this journal see, for example, Parker and Thomas 2011; see also Burrell and Morgan's seminal discussion of the paradigmatic underpinnings of critical management studies Burrell and Morgan [2015]). But such critical work itself may contain seams of its own kind of orthodoxy; equally here certain kinds of question characteristically might be 'off limits' (see, for example, Kilminster 2013). Moreover, Becker's defining concern is not so much the inherent politics of research - the question of 'Whose side are we on?' (Becker 1967) - but of the 
importance of 'looking elsewhere'. Thus, for instance, if we are interested in examining art as a form of collective action and social organisation it makes as much sense to start with an investigation of, say, the concerns of security guards in a public gallery as it does to commence with asking individual artists what it is that they 'do'.

\section{People 'Doing Things Together': Power, Structure and Agency}

Becker's consistent 'looking elsewhere' underpins, in part, his unwillingness to accept in any straightforward way the label of 'organisational theorist'. Yet, as he himself recognises, much of his work can be understood as being 'about organisations' to the extent that organisational research is primarily concerned with people 'doing things together' (see also Plummer's [2003] discussion and characterisation of Becker's work in this respect). This formulation - also the title of a collection of essays by Becker (Becker 1986) - is deceptively simple. In adopting it, Becker's stance is precisely to advocate an understanding of organisations as emergent relational and processual phenomena. In key respects, the formulation is at once anti-psychologistic and antiindividualistic. It is consonant with the broader corpus of his work in which Becker has been consistently concerned with individuals in the plural rather than 'the individual' as an isolated abstraction. In addition, the formulation 'doing things together' involves a conscious counter to the notion that 'organisations', 'structures', 'systems' and so forth can be considered as entities ontologically separate from the people who comprise them. In this vein, Becker is also anti-nominalist. In his sociological work, organisations are not considered to exist simply as categories of object - as solely discursive 'social constructions' (1986: 1-8) - they are consistently treated as real, emergent phenomena. One of Becker's favourite illustrations (see also Plummer 2003: 26; Becker 2008: 379-80) in this respect involves paraphrasing the words of the playwright David Mamet. As Becker recounted it to me during our interview:

In every scene in a play, everybody who is on stage, everybody who is in that scene is there for a reason, if they didn't have a reason to be in that situation, they wouldn't be there... but the thing is so are all those other people who are there - trying to achieve what they are trying to do. And what eventually comes out of it is what they are all willing to agree to... It is never anything that any one of them wanted. You know, it is never what they thought they were going to get when they got in, but it is like the best they could do with the moment. Alright 
that is a metaphor ... but it is a theory, it is a theory of how things work. It is very close ... to Bruno Latour's way of thinking about science.

Elsewhere, Becker has also described this 'emergent social order' metaphor as akin to Herbert Blumer's notion of 'collective action' (Becker in Plummer 2003: 26). Becker more generally rejects the classification of his own work as symbolic interactionist, but notes that this core insight, which forms a cornerstone of the symbolic interactionist approach as it was originally developed by the likes of Mead and Blumer, is probably 'the only part worth having' - the only part that he considers to be worth retaining (Becker in Plummer 2003: 26). In advocating a key facet of what, ostensibly, appears to be a classic symbolic interactionist stance, then, Becker looks to be adopting a position that has by now long been critiqued for its neglect of power, structure, and its over-stress on agency. However, Becker's position is rather more complex in this respect that it might initially appear.

To this end, a brief comparison with Norbert Elias's concept of 'figuration' may be instructive. In What is Sociology? (Elias 2012 [1970]) Elias commences his exposition of the concept of figuration by introducing a series of game models. The first of the models he presents involves an analogy that shares certain key characteristics with the Mamet/play example provided by Becker. It involves two relatively equally matched players engaged in a game of chess, each taking account of the other's move, such that the game begins to follow a course that neither had intended, and which becomes difficult to predict even several moves in advance. The game's changing course, its 'figuration', to use Elias's concept, in turn becomes something that both players become effectively 'subject to'. Elias develops a series of progressively more complex models to advance a cognate 'emergent order' principle, eventually modelling multi-tier contests which are analogous to large social organisations and nation states. In each case, Elias observes the complex ways in which human plans, intentions, decisions, actions combine and interlace to form a basic 'tissue' - an order that is greater and more compelling than any of the individuals who are the elementary units of its constitution. Like Elias, then, Becker here and elsewhere uses social (rather than, say, organic or mechanistic) metaphors to explain complex social phenomena. Contained in both the metaphors of a game and of a play, we might, for example, identify 'structure' modelled in Elias's case as a game's changing course, or in Becker's case as a kind of 
compromise or 'inertia' reached by people on stage through their collective action. Similarly, we might identify 'agency' here, variously, in people pursuing their own interests; seeking, with varying degrees of success, their own ends; engaged together in common practices and activities; and more generally trying to gain advantage or to 'win'. However, in both cases structure and agency are understood as effectively different facets of the same whole.iii

For Becker, different kinds of social formation are not 'supra-individual' in an ontological sense, but neither are they simply reducible to 'individuals' per se: they can come to have a degree of independence from any particular individual, but not from individuals as such. Moreover, in various parts of his sociological work, Becker has centrally explored social processes which encompass both social production and reproduction simultaneously. For example, as Robert Clulely (2012) has suggested, Becker's (2008 [1982]) work on Art Worlds might be said to depict, in the Giddensian sense, a form of 'structuration' (Giddens 1984; Cluley 2012). This is apparent in Becker's consistent focus upon the co-constitution of cultural texts and social structure through viewing as two aspects of the same process "how culture works as a guide in organizing collective action and how it comes into being', and how in art worlds, 'people pay attention to what other people are doing and, in an attempt to mesh what they do with others, refer to what they know (or think they know) in common' (Becker 1986: 19 cited in Cluley 2012: 204).

Becker's suggestion in the earlier-cited extract that the play/Mamet example invokes a principle that is consistent with the theoretical work of Bruno Latour is also noteworthy. In an interview with Harvey Molotch (2012), Becker notes that Latour's arguments in The Pasteurisation of France and Science in Action - in particular the notion that the fate of any particular scientific finding is, effectively, 'in the hands of the people who take it up' - were very similar to his (Becker's) own, only extended to a different substantive arena (Molotch 2012: 441). Indeed, the emergent order Becker illustrates through his paraphrasing of Mamet is in certain ways similar to Latourian concepts of 'machine' and 'assemblage' - in which independent parts combine in such a way that they come to comprise a level of integration at which each individual component is both controlled and controlling. As Becker expresses it elsewhere in exposition of Latour's principles: " "people are tied into the machine and the machine is tied into what they're 
doing, and you can think of that as a bigger machine". It's another way of talking about the same thing' (Becker in Plummer 2003: 26). Latour, conversely, has observed how Becker's work parallels his own in important respects (see Latour 2003: 144).

I asked Becker if he 'went along with the idea of assemblages, actor networks, and so forth'. Becker responded:

You know, Bruno likes to say that he takes science just as seriously as the people who do it take it, no more. That is to say, he doesn't fetishize it the way a lot of social scientists do with physical science... so I feel the same way about Bruno, I believe that theory just as much as he does. And no more. I think it is very obvious that Latour thinks of all that as something that he uses to understand the next thing he looks at.

Becker's observations concerning Latour's theoretical approach relate to his more general stance on theory, to which I will return later in this paper. However, for the moment, it is noteworthy that, at least on the face of it, Becker's approach to organisations as people 'doing things together' shares key commonalities with actor network theory, aspects of figurational sociology, and looks to be consistent with a broader 'relational/processual turn' within organisational scholarship (see, for example, Bakken and Hernes 2006; Chia 1996, 1999; Tsoukas 2001; Tsoukas and Chia 2002; Weik 2011) and the social sciences more generally (for a seminal discussion of this transition, see Emirbayer 1997), which centrally involves a shift away from substantialist thinking. Indeed, a common theme in much of Becker's work is the advance of fundamentally relational analyses of what are typically conceived of as 'individual phenomena'. For example, in his classic (1963) essay on 'Becoming a marijuana user' Becker convincingly demonstrates how 'drug effects' are anything but simple, unambiguous individual-level 'states'. He shows how the experience of using marijuana characteristically involves a dynamic interplay between a user's cognitions; the pharmacological action of the psychoactive alkaloids in the smoke itself; interactions with group members (notably more established users); a social stock of associations within which to locate and (re)frame certain 'effects'; plus the wider cultural/policy environments in which usage of the drug is defined as criminal or deviant (see, for a fuller discussion of this aspect of his work, Hughes 2003). Similarly, in Art 
Worlds (2008 [1982]), Becker effectively challenges the myth of art as simply 'the work of great, highly talented individuals'. He shows how 'All artistic work, like all human activity, involves the joint activity of a number, often a large number, of people'. Indeed, it is only 'Through their cooperation, the art work we eventually see or hear comes to be and continues to be' (Becker 2008: 1). As Bourdieu (1983) has recognised, Becker's focus on art as structured collective action facilitates an analytical shift away from 'the individual artist' and towards always a plurality of individuals - a shifting network of people who provide material resources, capital of various forms, channels of distribution, and who ultimately comprise the market for consuming the works thus created.

\section{Fields and Worlds: Becker and Bourdieu}

There are, nonetheless, some key differences in the work of Becker and Bourdieu. It is worth considering these differences both to facilitate a discussion in greater depth of the status of 'structure' in the work of Becker, and more generally to explore Becker's concept of 'world' as an organisational metaphor. Emirbayer and Johnson (2008) have argued that a key distinction to be drawn between Becker and Bourdieu pertains to what they call the 'interactionist fallacy', which involves, they propose, the analytical conflation of the structure of a field with the networks of interaction through which a field becomes visible (Bourdieu and Wacquant 1992: 113-14; Emirbayer and Johnson 2008: 8-9). In other words, the emergent order of an interactional network should not, they argue, be taken for all intents and purposes as one and the same thing as the 'struggle for the imposition of an organizing principle', itself based around the contestation over unevenly distributed economic, political, and positional resources (2008: 8). A similar distinction adopted by Giddens also means there are clear limits to the extent to which we might label Becker's work 'structurationist'. As we have seen, Giddens shares with Becker the idea that 'agents' and 'structures' are more a 'duality' than a 'dualism'. However, Giddens draws a clear distinction between 'structures' and 'systems'. The former he understands to be rules and resources that, as Giddens expresses it, both enable and constrain the relations between people, and which are 'instantiated' in 'recursive' patterns of social practice or 'systems' (Giddens 1984). To this end, Giddens considers 'structuration' to involve considerably more than the formation of emergent social systems. 
Bourdieu's explicit critique of Becker's Art Worlds follows from broadly parallel ontological contours to those of Giddens. Bourdieu argues that an artistic field cannot be reduced (as he alleges does Becker) to the sum of individual agents linked by simple relations of interaction or, more precisely, of cooperation: what is lacking, among other things, from this purely descriptive and enumerative evocation are the objective relations which are constitutive of the structure of the field and which orient the struggles aiming to conserve or transform it' (Bourdieu 1996: 205; Emirbayer and Johnson 2008: 9). Herein lies a core tension between the seemingly flat social ontology that Bourdieu reads from Becker's analysis, and Bourdieu's essentially realist, layered ontology which involves a variant of the Bhaskarian (1998) notion of a 'position-practice system' (see, for example, Vandenberghe 1999). In the latter, a sharp delineation must be drawn between 'things in themselves' as opposed to things as they are apprehended by the senses via their phenomenal characteristics. Critically, it also involves the clear possibility of things in themselves operating without observable consequences. Thus, a focus only on the apparent and emergent relations of collective social practices faces the distinct danger of neglecting, or altogether ignoring, the working of 'deeper' structures which are understood effectively to govern the conditions of, and possibilities for, such observable relational phenomena. Influential expressions of this core idea have been repeatedly formulated, albeit in a multitude of ways. The idea variously finds expression in the notion that a visible field of structural regularities is expressive of a priori governing conditions or, to cite a few key examples, 'noumenal' structures (Bachelard 1929); 'generative mechanisms' (Harré and Madden 1975); and 'tendencies and causal powers' which can only be analysed in and through the ways of acting of things (Bhaskar 1978 [1975]; 1998 [1979]).

However, such a critique of Becker's work holds only to the extent that one accepts the classic Kantian noumenal/phenomenal divide whereby 'deep structural mechanisms' supposedly beyond the ken of observation are understood to 'give rise to' visible patterns of relationship - imagery which, not by coincidence, is redolent of the classical structuralist surface/deep structure dichotomy. For Becker, such notions, such ways of visualising the social world, are unhelpful and misleading. Becker's arguments concerning cognate issues would suggest that, from his standpoint, the capacity to apprehend particular kinds of social relationship, particular 'social phenomena' is as much a question of analytical visibility as it is of the intrinsic 'ontological properties' of 
the social world. In this sense, 'structure' might be considered 'invisible' only to the extent that it is not (yet) properly understood, and 'deep' only in the sense of it entailing considerably greater complexity than face-to-face 'interactions'. iv

In an interview with Alain Pessin that is included as an epilogue to the $25^{\text {th }}$ Anniversary Edition of Art Worlds (2008), Becker centrally discusses the principal differences between his and Bourdieu's sociological approaches. In one part, Pessin suggests that a key distinction might be drawn between, on the hand, Bourdieu's sociological approach, which advocates the extrication of oneself, so to speak, from everyday knowledge in order to arrive at the 'truth about the social', and on the other, Becker's approach, which instead entails social analysts becoming immersed in lived practices, and otherwise maintaining a primary engagement with the processes in which people arrive at the 'shared understandings' that effectively constitute the 'only truths that the social world can produce' (Pessin in Becker 2008: 384). In his response, Becker evidently does not entirely concur with the idea that 'shared understandings' are the only 'truths' that can be produced, but equally, he rejects the notion that 'reality is hidden from ordinary mortals and that it takes a special competence, perhaps even a magical gift, to be able to see through these obstacles and discover The Truth' (2008: 385). Becker recounts some of the ideas of his mentor, Everett Hughes, to further elaborate upon his own position in this regard:

he often said that sociologists did not know anything that nobody knew. Whatever sociologists knew about social life, they had learned it from someone who was part of and fully engaged in that area of life. But since Simmel had made clear in his essay on secrecy [1950], knowledge is not equally distributed, everyone doesn't know everything. Not because people are blinded to reality by illusions, but because things have been kept from them by institutional arrangements (which may or may not have been put in place to achieve that end). Sociologists find out what this one knows and that one knows so that, in the end, they can assemble the partial knowledge of participants into a more comprehensive understanding. The idea of 'false consciousness' is a classic example of the theory of social knowledge opposed to my own practice. (2008: 385-6) 
Becker thus recognises the social contingency of knowledge - of how, in particular, certain 'institutional arrangements' can (sometimes through intent) serve as a constraint over the apprehension of certain aspects and facets of the social world. However, for Becker, the idea that observable social relationships constitute a kind of 'froth', that needs, analytically speaking, to be 'wiped away' so as to probe into 'deeper' 'generative' structures in a quest to discover 'the truth' involves conceptual imagery which is profoundly at odds with his own. Such notions, he suggests, appear to be based upon a kind of mythological conception of the 'heroic social analyst' who seemingly assumes a special kind of epistemic privilege in apprehending the world. The 'visibility' of social phenomena is for Becker fundamentally related to both the complexity of social relationships and to levels of knowledge about the world. Indeed, much depends on the very metaphors we use to understand and approach particular kinds of social practice. In this respect, he advances a kind of pragmatist epistemological principle as the crucial test of any particular theoretical lens or metaphor. In using any particular concept or metaphor, Becker proposes, we might ask what can now be seen that was previously invisible? What questions can now be answered that had previously have been ignored? What operations can now be undertaken with a firmer and clearer evidential basis? (Becker 1986: 2). In considering Bourdieu's concept of field, Becker finds a number of key restrictions in these respects.

Becker's core critique of Bourdieu's concept of field is that the metaphor is, in many ways, a highly restrictive one. It is a metaphor that, in a lineage that runs from Ernst Cassirer's (1953 [1923]) neo-Kantian philosophical work on mathematics and concept formation through to Kurt Lewin's (1936) vector psychology, ${ }^{\vee}$ involves imagery imported from physics to invoke, for example, 'fields of forces' akin to, say, magnetic fields (see for a fuller discussion of the development of field theory, including Bourdieu's position within it, Martin 2003). It is also a spatial metaphor, and at that, Becker observes, a somewhat claustrophobic one. The space within a field, so it is understood, is always finite, and as such, people are typically seen to be struggling over limited 'space' - be that analogous of power under diverse guises, constrained resources, or positional access of various kinds (Becker 2008: 373). This finitude also means that not all moves are possible - that human exchanges are always zero sum: one person's gain is another's loss. Employing this conceptual imagery, Becker suggests, means from the outset invoking a metaphor in which adversarial struggle 
over positional advantage is effectively anticipated as an a priori characteristic of the relationships so modelled. In Bourdeusian field analysis, an orientation towards understanding the world as 'fields' seemingly permits and facilitates the apprehension and inference of the workings of enduring structures; typically those pertaining to social class, gender, ethnicity and so forth. However, in adopting such a lens - of 'confinement', 'compression', 'scarcity' - social relationships invariably appear to be oppositional, with virulent struggles over scarce resources stylistically 'baked into' an analyst's underpinning ontological precepts. The metaphor of field, then, renders visible only conflict, restriction, containment, restraint and, by extension, relationships of domination/subordination, coercion and control. When employed as a model of organisation, all relationships and practices are effectively homologized through a monolithic logic of practice (see, for a parallel critique of Bourdieu, Friedland 2009). Accordingly, what might appear to be 'scientific discovery' may in fact be more the product of the metaphorical style of a particular mode of analysis. To put it provocatively, 'hidden truths' may be more superimposed than 'uncovered' through the application of field.

For Becker, the question of what is made analytically invisible when one employs the concept of field also remains to be a pertinent one. The dangers of the concept of field are realised, for example, in assuming that particular arenas of social life are 'closed', in the sense that a particular group has monopolised access to participation within a specific sphere of activity (Becker 2008: 375-6). For instance, if we consider the discipline of sociology as an 'academic field' in the Bourdieusian sense, we are immediately oriented towards how it is that certain key individuals and groups have a high degree of control over who can and cannot become engaged in that form of collective activity. People who are denied access to this field cannot become sociologists; they find it difficult to engage in sociological research, get published in sociological journals, and so forth. One might attempt to undertake sociological work independently, perhaps without an institutional affiliation. But even if successful, such success is limited to the extent that the work would not be recognised by those who control the sociological field. However, Becker suggests, such monopolies are rarely, if ever, complete and permanent (2008: 376-7). For Becker, the question of success in the case of the sociologist without affiliation - indeed, the more general degree to which heterodox ideas might influence and come to be accepted by 'important people' 
- is always an empirical question, not simply a question of how one conceptualises the social world. For example, if we compare the practice of academic sociology in France with that of the US, the 'field' is very different. The sheer number of sociologists in the US (something like 20,000 by Becker's estimation) means that it is possible to research seemingly any niche area: nothing is too specialist. It is also potentially much easier to find similar others to 'march under the same flag', so to speak; it is often possible to recruit others who share an interest in a narrow specialism from this huge number. If one is able to recruit a sufficient number of like-minded types, Becker proposes, it may be possible to organise your own section of the ASA, start your own journal (e.g. the international Visual Sociology Association), elect your own president, and so on. If someone is monopolising the field in which you are working, it is always possible to 'look elsewhere'; perhaps you may even have a major new field to yourself for a while (2008: 377-8).

Becker's concept of world, then, has certain key differences from that of 'field'. Like all concepts, Becker suggests, it is still a metaphor of sorts. However, it is not a metaphor that conjures images of a playing field, or a force field, or a kind of box with photons shooting in different directions (Becker 2008: 374). But even if we were to still think of 'world' in spatial terms - and Becker insists it should not be approached as a spatial metaphor - it is far more expansive a metaphor than that of field. It is a metaphor oriented empirically towards people 'trying to get things done' (2008: 379). In social worlds, Becker argues, people are understood not to be responding 'automatically to mysterious external forces surrounding them'. But rather, as developing 'their lines of activity gradually, seeing how others respond to what they do and adjusting what they do next in a way that meshes with what others have done and will probably do next' (2008: 376). The lines that are drawn around 'social worlds' (often to separate them from what they are not) do not correspond to discrete empirical 'boundaries', they are invariably constructed for analytical convenience.

Considering organisations as 'worlds', then, demands a cognitive shift away from imagining discrete social worlds that begin and end with the physical boundaries of particular premises, or that are delimited by recognised ties of affiliation and membership. Such physical and discursive demarcations are not without their significance. However, for the purposes of social analysis, they should not be taken to 
define in any simple or straightforward sense the empirical objects of investigation (Becker 2008: 376). Indeed, assuming that one is about to encounter a 'bounded' or 'contained' 'field' might predispose a social analyst towards ignoring emergent forms of involvement, association and influence within a social world. For example, Dickinson (2008) - who provides something of a comparative application of the concepts of 'field' and 'world' - shows how new and developing forms of news dissemination, such as blogging and citizen journalism have come to have a profound influence over the established 'field' of professional journalism despite their somewhat ambivalent relationship to established forms of news media. As Dickinson observes, the degree to which 'closure' or 'confinement' exists within any particular sphere of collective activity is thus always an empirical question (2008: 1394).

In one part of the interview with Becker in the anniversary edition of Art Worlds, Pessin explains that in comparison of Becker's and Bourdieu's work on art, Becker is commonly depicted as, to adopt a photographic metaphor, the analyst who uses a telephoto lens, whereas Bourdieu, so it is understood, employs the wide-angle. The charge is that Becker neglects 'the bigger picture' (class, relations of domination, social power) but instead provides an elaborately detailed micro sociology of discrete social worlds. However, as we have seen, Becker's arguments suggest that the reverse is more the case to the extent that field is restrictive in a simultaneously spatial and analytical sense, where as world is considerably more expansive and 'opened out'. In my own interview with him, I asked him what he thought of this reversal of the photographic lenses comparison:

Yes, yes ... and Latour is the obvious proponent of that way of thinking too because you know, the difference between network and world is not so enormous, I mean they are both metaphorical but they are kind of open metaphors that let you add things. They don't commit you to so much. And the field metaphor - the way that Bourdieu used it - really is very constraining. It limits you to the topic of zero sum gain... well look at the book that Rob and I did [Faulkner and Becker 2009]. That is not a zero sum game. When we get on the stand, the object is to find something that we will all be happy enough with, that we can get through the night with. And doing that successfully is a positive sum gain, everybody gets something. 
Becker's concept of world, then, is far more open to the possibility of cooperation, mutual engagement, collaboration as emergent forms of collective action than Bourdieu's concept of field. However, that said, 'world' does not presuppose these forms of social relationship. Crucially, Becker proposes, a focus upon mutual engagement does not obviate a consideration of conflict and contestation. Adversarial contests between employers and labour unions; new strategies of worker resistance in response to normative control system; struggles over employee performance, task discretion and job intensification; and so forth - all are examples of 'people doing things together', albeit with a balance of outcomes that neither 'side' had fully indeed. Becker argues that conflict can easily be worked into the notion of world, so long as it is understood as an aspect of a particular relationship, not an a priori determining principle. The primary focus of analyses of social 'worlds', Becker states, is upon the question of 'who is doing what with whom', whereas the fundamental question of an analysis that employs the concept of field is 'who dominates who, using what strategies and resources, with what results?' (2008: 385). For Becker, these kinds of questions can, and frequently are, considered in an analysis of worlds, but typically only as a subset of the other more general questions that might be asked. But the more general set of questions enabled by Becker's concept of world 'cannot be easily raised by an analysis centred on Bourdieu's notion of field. Most of them, it seems to me, are a priori set aside as trivial in comparison with the "big questions" of dominance and forces' (2008: 384-5).

\section{Language and Conceptual Totems}

The 'openness' of the concept of world, and in particular, the formulation of organisations as 'people doing things together' might wrongly convey the impression that Becker considers social life to be more amenable to adaptation, change, and voluntaristic impulse than it actually is (Becker 2008: 380). Such connotations, Becker suggests, would be somewhat unwelcome since social life evidently does have regularities, people generally do not act in entirely spontaneous ways, and there are indeed notable enduring characteristics to many aspects of everyday life. However, Becker pointedly stops short of referring to 'structure' and 'power' to explain such enduring regularities. In my interview with him, I asked him if in not using the terms he had neglected these concerns. He suggested that, conversely, in not using the terms, 
he was consciously avoiding the baggage that came with them. Of significance, in this connection, is the shadow of Parsons and other similar figures who developed grand scale social ontologies in relative isolation from empirical research. This divorce of theory and research and concomitant conceptual formalism is clearly something at odds with his own sociological practice. Becker also mentioned how anthropologists such as Meyer Fortes and Raymond Firth variously 'spoke about structure in this kind of mystical way'. Becker wanted to avoid such ways of thinking about structure, thus he:

intentionally neglected it in the sense that I just described it... but in so far as structure, if I redefine it as people recognising other people, defining other people as likely to do this and that, so I better pay attention... I'm not a fool! I understand all of the manifestations of power, so it really comes down to a kind of religious thing: am I going to say the word or not? ... You see I have referred to what some people talk about that way very often as 'inertia'. In other words, you know, nobody is exerting power to make me play a piano that has 88 keys on it, and that the notes of which can be notated on a staff of five lines, etc. That is there and it stays there because most of the people who are involved with such things recognise it, and it is useful to them in getting on with what they do to recognise that. So when I arrive, you know, I don't have a whole lot of choice. I can start all over again, and people have done that, or I can say well that is the way it is, that is the 'power' of 'social structure'. Well that is not the power of social structure, that is the 'power' of people doing things in the way that is most convenient for them because it has been set up in years past.

Becker's insistence on using terms like 'inertia' or, elsewhere, 'convention' and 'repertoire' (Becker and Faulkner 2008) is thus expressly intended to avoid a reification of 'power' and 'structure' as entities beyond the level of human relationships that, in turn, exert influence over those relations, and which somehow undergird all forms of 'collective action' vi Also of significance is Becker's comment that the use of such terms is 'a kind of religious thing'. This point relates to more than mere linguistic preferences: it is arguably indicative of Becker's more general stance concerning the tendency in the social sciences towards a treatment of concepts and particular linguistic signifiers as conceptual amulets, together with a more general fetishisation of 'social theory'. Chris 
Rojek and Bryan Turner (Rojek and Turner 2000) have described this prevailing tendency as comprising a 'decorative turn' in the social sciences. To simplify somewhat, the decorative turn involves the dominant tendency to employ theory, particularly that which is in vogue, in a manner which serves principally to adorn or otherwise 'decorate' empirical analyses. Theory employed in a 'decorative' manner is characteristically projected on to research, rather than developed in tandem with it. It is used to lend ostensible veracity and rigour to otherwise relatively pedestrian empirical observations. Such tendencies, in turn, can be understood as in part responses to a publication/promotion environment in which lexical sophistication is actively encouraged and is often treated as a proxy for academic value. Becker has discussed this tendency at length in his somewhat iconoclastic Writing for Social Scientists (1986). These arguments have also been taken up more recently by Michael Billig in Learning to Write Badly: How to Succeed in the Social Sciences (Billig 2013). In personal e-mail correspondence, Becker nicely summarises his position on theory in this respect:

The establishing of a dominant paradigm in our racket has to be a sociological phenomenon, not something that will ever be settled by epistemological (or any other kind of philosophical or 'theoretical') arguments. It has always been settled by people getting small semi-monopolies here and there over the training of graduate students and disciples, the control of journals thought to be influential, and of other publishing outlets (this is one of the ways Bourdieu got to be so dominant for a while in France). And the ability to do that depends on the ground the fighting takes place on. Bourdieu could gain control with the kinds of heavy theoretical arguments he made because a couple of generations of French sociologists got their basic undergraduate training in philosophy, were adept at such arguments, and admired people who did that kind of thing well... Talking at more abstract levels, the kinds of general statements that typically constitute theory, as an end in itself, trying to generate better general ideas, is probably a waste of time. I know that many, perhaps most, sociologists today, won't agree with me... But what I've observed over the years is that good research tends to be remembered and be influential while theories just ... go away. I mean, seriously, who reads Talcott Parsons any more besides Jeff Alexander? Who reads, to mention more arcane names, Howard $\mathrm{P}$. Becker (well-known as a theoretician in his day) or Pitirim Sorokin... I predict ... that Bourdieu will suffer 
the same fate. As will others who aspire to his now (temporary) hegemonic position over this area of collective endeavor.

Becker's comments above help explain why it is that he has pointedly 'looked elsewhere' in the sense of his tendency not to have adopted more general concepts from the social sciences. Again, this can be understood to be related to his sociological practice in which theory is never treated as an end in itself. Somewhat paradoxically, in this respect he shares considerable common ground with Bourdieu who has similarly written in critique of what he calls 'theoretical theory' or theory without object. In theoretical theory, Bourdieu proposes, theory is effectively treated as a substitute for research. What comes to count as 'theory' invariably takes the form of sterile, abstract self-perpetuating polemics which involve 'vacuous meta-discourse around concepts treated as intellectual totems' (Bourdieu in Wacquant 1989: 50). In turn, the enterprise of theoretical theory leads to a proliferation of ' ....endless and unassailable "conceptual melting pots" of neologisms, refurbished categories, and pseudo-theorems, generally closed by a call for further research or empirical application, preferably by others' (Bourdieu in Wacquant 1989: 50).

Elsewhere in our email correspondence, Becker has recounted his teacher Everett Hughes's response to students who asked him what he thought about 'theory'. 'Theory of what?' was his inevitable, highly pragmatist, reply. Indeed, Becker's advice to me in pursuing various questions of theory with him was ultimately that I was probably wasting my time since there is simply too much in the world worth finding out about: in other words, l'd be better off 'getting on with the work'.

\section{Conclusion}

In this paper, I have centrally argued that Becker's conceptualisation of organisations as people 'doing things together', and his conceptual metaphor of 'world' hold considerable value to researchers engaged in organisational/industrial scholarship. I have sought to advance a characterisation of Becker as something of an 'unwilling' organisational theorist. I have suggested that this 'unwillingness' or reluctance to accept that depiction relates in part to a more general stance concerning his sometimes conscious rejection of certain aspects of formal theory. In turn, this tendency, I have argued, is bound up with Becker's sociological practice in which he 
has consistently 'looked elsewhere'. Looking elsewhere involves reformulating social problems such that they pertain less to eternal abstract conceptual dilemmas or, in other cases, false assumptions about the character of that which is considered. For example, problems of deviance might be reconsidered not as pertaining to the central question what makes them do it, but to a question of how do some behaviours, and some people come to be understood to be deviant, while others are not. The question, what can be truly said to constitute art is similarly reimagined: away from an insoluble concern with classification and aesthetics, and towards an empirical consideration of particular social practices in which we might consider how what particular groups deem as 'art' comes to be produced. Of particular value to organisational/industrial scholars is Becker's consistent ability to reconceive of 'individual acts', on the one hand, and 'social structures', on the other, as invariably 'people doing things together'. I have discussed in some detail how such a formulation arguably accommodates and possibly transcends certain problems of structure and agency.

Overall, I have argued that a key facet of Becker's work resides in his capacity to translate, to the extent that we can draw a neat line of delineation, abstract philosophical questions into concrete, researchable ones. Becker does not play the 'social theory' game, or at least, he does not do so in any kind of conventional way. But that depiction of social theory - as but one game, one way to go, among many others, nothing to get particularly het up about - is very much a motif of his sociological practice. As Harvey Molotch (2012: 423) has suggested, Becker's empirical embrace of the informal and the mundane, his rejection of all forms of intellectual pretentiousness, marks out many of the distinctive characteristics of his more general approach to sociology. Becker's radicalism finds expression, for example, not so much in abstract polemics about structural antagonisms, but in, say, his critique of the inherent elitism involved in the politics of academic writing and research; and in other ways paying attention to topics, concerns, issues which run counter to the more general direction of travel within the social scientific establishment. It is also perhaps noteworthy that, while Becker's work on deviance and education, to take just two examples, was not centrally concerned with problems of social class it, perhaps more than any other scholar of his era, has been readily extended to analyses of class, social control, and more general relationships of dominance and subjugation, by a multitude of subsequent researchers. 
For the study of organisations, then, Becker's work might be boiled down to a few core elements - a kind of manifesto for looking elsewhere:

1. Looking elsewhere typically means proceeding from the understanding that official or received accounts of how organisations function and operate are likely to be significantly at odds with how they actually function and operate. In much of his ethnographic work, Becker is interested in why and how rules are circumvented and broken, and in how seemingly irrational behaviours and attitudes are often quite rational and understandable when understood from the perspective of those who engage in them. In this way, we might understand Becker's work - particularly its concern with deviant and abnormal behaviours as a fore-runner of more recent organisational scholarship primarily concerned with the 'grey zones' and 'dark sides' of organisations (see, for example, Linstead, Maréchel and Griffin 2014).

2. In relation to the latter, Becker is consistently sensitive to the problems with which different groups concern themselves. This informs both his way of 'seeing' and his way of 'looking at' organisations. For example, his view of organisational culture as shared solutions to a common set of problems is grounded in the idea that shared values emerge from people 'doing things together', not simply by decree from the 'standard practices division', or from a consultancy-penned mission statement. Similarly, Becker might ask organisational researchers to ask themselves 'whose question are you asking'? Are researchers asking questions which follow the interests of those in the power apex of the organisations considered - questions, say, about how best to enhance the productivity of employees, reduce absenteeism, monitor workflows, and so forth? Or do their questions stem more from the concerns of a particular intellectual community - perhaps an engagement with issues of, say, power, subjugation and the labour process that might follow from being a critically minded organisational scholar? Becker's characteristic approach is not altogether to dismiss either set of concerns, but rather to consider what kinds of questions might be 'off limits' when we concern ourselves solely, perhaps exclusively, with the problems with which a particular group (including our own professional and intellectual group) are preoccupied. Accordingly, he alerts us 
to consider the problems with which those we study are concerned since these might allow us to reframe our own questions and lines of investigation.

3. Becker's work typically sensitises researchers to the marginal and exceptional. It follows in a tradition of Chicago School research on offbeat, dirty and minority occupations - the so called 'nuts and sluts' tradition (Watson 1997; Badham et al. 2003: 5). In this sense 'looking elsewhere' involves a kind of ethnographic version of the 'null hypothesis trick' (see Becker 1998). If a researcher is interested, for example, in how rules concerning dress codes within an office are established and maintained, following Becker, we might look where we expect to find no rules - perhaps a dress-down Friday. Here, to continue with the same example, we might find an unspoken dress code at play, albeit that it is not formally articulated in the manner of a uniform, nor 'policed' in any conspicuous manner. Becker's work thus encourages researchers to find 'ways in' to particular problems and the empirical sites to which they pertain that are counter-intuitive and 'unconventional'.

4. Again, following on from the point above, Becker throughout his work has consistently maintained a fundamental engagement with 'convention'. This engagement sometimes surfaces as a scepticism concerning dominant analytical convention. His hesitance concerning the use of terms such as 'power', 'structure' and 'agency' is a case in point. Becker's approach is not so much to avoid or altogether shun the use of conceptual terminology, but rather, to encourage a reflexive engagement with concepts; to avoid unnecessary lexical complexity; and to ensure that concepts and terminology are germane to the problems with which we concern ourselves. Becker's work is thus not so much anti-theory, but rather, is anti-theory-without-object. His sociological practice - and explicit advice - steers a researcher away from a concern with 'social' or 'organisational theory' in a general and abstracted sense, and towards a consideration of theoretical questions only as part-and-parcel of discrete investigations of concrete empirical phenomena. Becker would thus likely find little analytical value in the complex and sophisticated polemics concerning 'high' theory which sometimes grace the pages of this journal and others similar. Indeed, he would see intellectual time and effort as better spent pursuing concrete research problems than dwelling on the nuances of conceptual architecture (present discussion included). 
5. That said, I have argued throughout this paper that irrespective of whether or not Becker can be said to be a organisational theorist in a formal sense, his work nonetheless has major theoretical significance. Of particular significance are the idea of organisations as 'people doing things together', and the imagery of 'world' as ways of 'seeing' and 'looking at' organisations. Here 'looking elsewhere' involves an epistemic 'openness' to avoid, say, assuming either inevitable conflict or consensus in the relationships we study. It also involves an engagement with concrete social relationships and processes. In this sense, I have suggested, Becker's 'looking' elsewhere to a degree accords with a more general 'turn' to relational and processual anti-substantialist thinking in the social sciences.

In these ways and others, Becker's work anticipates some of the key developments in the field of organisational studies over the last several decades. There are important parallels with other approaches, notably those that centrally employ the metaphor of networks as the cornerstone of their analyses, and which more generally form part of a shift away from an engagement with 'essences' and towards an engagement with 'flows'. However, arguably the most significant aspect of Becker's sociological practice resides not so much in how it might be characterised, how it might address, or not, some of the debates that have come to dominate the field or organisational research in recent years, but in terms of the tremendous range of insight it has demonstrably been able to realise. The 'model' contained within Becker's sociology in this respect is not a model comprised of conceptual formalism, but a model of intellectual practice and at that, one that offers considerable potential for organisational scholars who are willing to 'look elsewhere'. 


\section{References}

Bachelard, G. (1929) Le Nouvel Esprit Scientifique. Paris: Librarie Félix Alcan.

Badham, R., Garrety, K., Morrigan, V., Zanko, M. and Dawson, P. (2003) 'Designer deviance: enterprise and deviance in culture change programmes'. Organization, 10(4): 707-730.

Bakken, T. and Hernes, T. (2006) 'Organizing is both a verb and a noun: Weick meets Whitehead'. Organization Studies, 27(11): 1598-616.

Becker, H. S. (1963) Outsiders: Studies in the Sociology of Deviance. New York: Free Press.

Becker, H. S. (1967) 'Whose side are we on?'. Social Problems, 14(3): 239-247.

Becker, H. S. (1986) Doing Things Together: Selected Papers. Illinois: Northwestern University Press.

Becker, H. S. (1986) Writing for Social Scientists. Chicago: University of Chicago Press.

Becker, H. S. (1995) 'The power of inertia'. Qualitative Sociology, 18(3): 301-309.

Becker, H. S. (1998) Tricks of the Trade: How to Think About Your Research While You're Doing It. Chicago: University of Chicago Press.

Becker, H. S. (2008) [1982] Art Worlds. 25 ${ }^{\text {th }}$ Anniversary Edition. London: University of California Press.

Becker, H. S. (2012) Personal email correspondence with Author.

Becker, H. S., Geer, B., Hughes, E. C. and Strauss, A. (1961) Boys in White: Student Culture in Medical School. Chicago: University of Chicago Press.

Bhaskar, R. (1978) [1975] A Realist Theory of Science. Hemel Hempstead: Harvester Wheatsheaf.

Bhaskar, R. (1998) [1979] The Possibility of Naturalism. 3rd ed. London: Routledge.

Billig, M. (2013) Learning to Write Badly: How to Succeed in the Social Sciences. Cambridge: Cambridge University Press.

Bourdieu, P. (1983) The Field of Cultural Production: Essays on Art and Literature. Cambridge: Polity.

Bourdieu, P. (1996) [1992] The Rules of Art: Genesis and Structure of the Literary Field. Trans. Susan Emanuel. Stanford: Stanford University Press.

Bourdieu, P. and Wacquant, L. (1992) An Invitation to Reflexive Sociology. Chicago: University of Chicago Press.

Burrell, G. and Morgan, G. (2015) Sociological Paradigms and Organizational Analysis. (2nd Edition), Aldershot: Ashgate. 
Cassirer, E. (1953) [1923] Substance and Function, and Einstein's Theory of Relativity. New York: Dover.

Chia, R. (1996) Organizational Analysis as Deconstructive Practice. Berlin: de Gruyter.

Chia, R. (1999) 'A "rhizomic" model of organizational change and transformation: perspective from a metaphysics of change'. British Journal of Management, 10: 209-27.

Cluley, R. (2012) 'Art words and art worlds: the methodological importance of language use in Howard S. Becker's sociology of art and cultural production'. Cultural Sociology, 6(2): 201-216.

Dalton, M. (1959) Men Who Manage: Fusions of Feeling and Theory in Administration. New York: Wiley \& Sons.

Dickinson, R. (2008) 'Studying the sociology of journalists: the journalistic field and the news world'. Sociology Compass, 2(5): 1382-1399.

DiMaggio, P. (1970) 'On Pierre Bourdieu’. American Journal of Sociology, 84(6): 14601474

Dunning, E. and Hughes, J. (2013) Norbert Elias and Modern Sociology: Knowledge, Interdependence, Power, Process. London: Bloomsbury Academic.

Elias, N. (2012) [1970] What is Sociology? Edited by Artur Bogner, Katie Liston and Stephen Mennell. Dublin: UCD Press. (Collected Works, vol. 5). First published in German as Was ist Soziologie, Munich: Juventa, 1970.

Emirbayer, M. (1997) 'Manifesto for a relational sociology'. The American Journal of Sociology 103(2): 281-317.

Emirbayer, M. and Johnson, V. (2008) 'Bourdieu and organizational analysis'. Theory and Society. 37: 1-44.

Faulkner, R. and Becker, H. S. (2009) "Do You Know...?" The Jazz Repertoire in

Action. Chicago: University of Chicago Press.

Friedland, R. (2009) 'The endless fields of Pierre Bourdieu'. Organization, 16(6): 887917.

Giddens, A. (1984) The Constitution of Society. Cambridge: Polity.

Harré, R. and Madden, E. (1975) Causal Powers: A Theory of Natural Necessity. New Jersey: Rowman \& Littlefield Publishing Group.

Hughes, J. (2003) Learning to Smoke: Tobacco Use in the West. Chicago: University of Chicago Press. 
Jackall, R. (1988) Moral Mazes: The World of Corporate Managers. Oxford: Oxford University Press.

Kilminster, R. (2013) 'Critique and overcritique in sociology', Human Figurations, 2(2) http://hdl.handle.net/2027/spo.11217607.0002.205

Latour, B. (2003) 'What if we talked politics a little?'. Contemporary Political Theory, 2: 143-164.

Lewin, K. (1936) Principles of Topological Psychology. New York: McGraw-Hill.

Linstead, S., Maréchal, G. and Grifin, R. (2014) 'Theorizing and researching the dark side of organization'. Organization Studies, 35(2): 165-188.

Martin, J. (2003) 'What is field theory?'. American Journal of Sociology, 109(1): 1-49.

Moeran, B. (2012) 'Opinions: what business anthropology is, what it might become... and what, perhaps, it should not be'. Journal of Business Anthropology, 1(2): 240297.

Molotch, H. (2012) 'Howard S. Becker Interview by Harvey Molotch'. Public Culture, 24(2): 421-443.

Parker, M. and Thomas, R. (2011) 'What is a critical journal?'. Organization, 18(4): 419-427.

Plummer, K. (2003) 'Continuity and change in Howard S. Becker's Work: An interview with Howard S. Becker'. Sociological Perspectives, 46(1): 21-39.

Rojek, C. and Turner, B. (2000) 'Decorative sociology: towards a critique of the cultural turn', Sociological Review 48(4): 629-648.

Tsoukas, H. (2001) 'Re-Viewing Organization', Human Relations 54: 7-12.

Tsoukas, H. and Chia, R. (2002) 'On organizational becoming: rethinking organizational change'. Organization Science, 13(5): 567-82.

Vanderberghe, F. (1999) "The real is relational": an epistemological analysis of Pierre Bourdieu's generative structuralism' Sociological Theory 17(1): 32-67.

Wacquant, L. (1989) 'Toward a reflexive sociology: a workshop with Pierre Bourdieu', Sociological Theory 7(1): 26-63.

Watson, T. (1997) Sociology, Work and Industry, 3rd edn. London: Routledge.

Weik, E. (2011) 'In deep water: process theory between the Scylla and Charybdis'. Organization, 18(5): 655-672.

Zald, M. (2002) 'Spinning disciplines: critical management studies in the context of the transformation of management education'. Organization, 9(3): 365-38. 


\section{Notes}

i The historical relationship between the emergence of 'management and organisational studies'
and the 'transformation of disciplines' has been discussed in detail elsewhere. See, in particular,
Zald (2002).
ii Badham et al. (2003) have drawn extensively on Becker's work to explore in depth some of
the issues Becker alludes to concerning culture change. Drawing upon Becker, we can observe
how 'culture change' initiatives typically bear all the hallmarks of 'moral crusades', proceeding in
part by stigmatising behaviours that deviate from corporate norms. The problem that employees
typically then have to solve is how to avoid such stigmatization whilst meeting the expectation of
having wholeheartedly 'bought in' to a kind of enforced corporate gemeinschaft. However, for
Badham et al. deviance does not simply exist as counter-culture. In their analysis of a culture
change programme at 'Sprogworks', a large Australian corporation, Badham et al. found
deviance effectively mobilized in the service of a culture change initiative, whereby a 'deviant
radicalism' came to be championed in favour of 'deviant conservatism'. They show how the
dynamics of deviance and culture change are multifaceted and complex: under some conditions
deviance can become subsumed within the very normative systems to which such behaviours
originally ran counter.
iii It is beyond the scope of this paper to undertake a systematic comparison between the work
of Becker and Elias. Elias is arguably more concerned with the longue durée than Becker, and
there are important differences between Becker and Elias in relation to the latter's focus on
interdependence. Nonetheless, as has been highlighted elsewhere (Dunning and Hughes 2013 :
$149-50)$, there are clear lines of compatibility, particularly in respect of Becker's orientation
towards 'process'. iv Once again, Elias's concept of 'chains of interdependence' (Elias 2012) - increasingly complex, often asymmetrical, multi-directional power relations which extend considerably beyond face-to-face encounters - is here a useful counterpoint to the concept of 'interaction'. Consider, for example, how a typical European breakfast involves enduring ties between people who typically never meet, are often separated by continents, and yet are still profoundly bound together in chains of interdependence - themselves expressive or enormous social/structural complexity. Chains of interdependence are 'deep' in as much as they span enormous complexity and constitute long-term social processes. Indeed the spatial metaphors of 'depth' and 'visibility' are at odds, in important ways, with the relational/processual thinking of Elias. Equally dangerous, for Elias, are others such as the common tendency towards an overextension of linguistic analogies, such as the distinction between langue and parole. To put it crudely, thinking of 'structure' as akin to 'grammar' and 'agency' as akin to 'speech' involves precisely the kinds of ontologically specious separation and dualistic thinking that grand scale synthesizing ontologies, such as that of Giddens, sought to transcend.

The influence of the work of both figures is apparent in relation to several aspects of Bourdieu's conceptual architecture, the concept of field is principal among these (see, for example, DiMaggio 1979; Emirbayer 1997; Martin 2003).

vi Becker discusses his alternatives to 'power' and 'structure' in numerous places, see in particular Becker (1995). 